\title{
DETECTION AND DELINEATION OF SUBSURFACE COAL MINE FIRE FROM SPACEBORNE THERMAL INFRARED DATA IN JHARIA COALFIELD, DHANBAD, INDIA
}

\author{
Shanti Swarup Biswal ${ }^{1, *}$, Amit Kumar Gorai ${ }^{1}$ \\ ${ }^{1}$ Department of Mining Engineering, NIT Rourkela, Odisha, India - shantiswarup@live.in
}

KEY WORDS: coal fire, thermal infrared, GIS, spaceborne, ASTER, Landsat 8

\begin{abstract}
:
Coal fire has been found to be a major problem worldwide in coal mining areas. The surrounding areas get hugely affected, and significant amount of reserves are wasted due to the burning of coal. This severely affects the environment condition, which leads to a rise in temperature of the region, which is a major reason for climate change. Greenhouse gases like $\mathrm{CO}_{2} \mathrm{SO}_{2} \mathrm{NO} \mathrm{CH}_{4}$ are also emitted from the cracks and fissures. Large masses of the burning of coal also causes land subsidence and collapse. Underground coal fires ignited by natural causes or human error leads to atmospheric pollution, acid rain, land subsidence, and increased coronary and respiratory diseases. They consume a valuable energy resource, destroy floral and faunal habitats, and promote human suffering because of heat, subsidence, and pollution. Jharia Coalfield, Jharkhand, India, is well known for being the storehouse of prime coking coal and for accommodating the maximum number of coal fires among all the coalfields in the country. In this paper, some of the important issues of coal fire mapping from satellite thermal infrared data have been addressed in particular reference to Jharia Coalfield. Namely, these are: retrieval of spectral radiance from raw digital satellite data using scene-specific calibration coefficients of the detectors from metadata, thermal emissivity of surface to obtain kinetic temperature at each ground resolution cell of satellite data, field-based modelling of pixel-integrated temperature for differentiating surface and subsurface fire pixels in Landsat 8 thermal IR data, identification of surface coal fire locations from infrared data and lateral propagation of coal fire.
\end{abstract}

\section{INTRODUCTION}

Coal is formed from the leftovers of primeval vegetation that was accumulated in swamplands and peats. The energy, i.e. generated from coal is the energy that was absorbed by vegetation from the sun billions of years before (The Coal Resource, 2002). Coal nowadays is used in various ways such as for production of electrical energy ( $41 \%$ of universal electrical energy is run by coal-fired power plants), steel ( $70 \%$ of steel produced today uses coal), cement $(200 \mathrm{~kg}$ of coal needed to produce 1 tonne of cement) and aluminium (50\% of the energy used to produce aluminium is generated from coal). Today, China, USA, India, Australia, and Indonesia are one of the largest coal-producing countries across the globe (Dillinger, 2019). Worldwide, currently, over 7269 million tonnes (Mt) of hard coal and $787 \mathrm{Mt}$ of lignite are produced (Coal Information, 2017). Almost all countries have a coal reserve, but only 70 countries have recoverable reserves. The biggest reserves are in the USA, Russia, China, and India. Undoubtedly, coal plays an important role in providing fuel to all the industries, but it also creates an environmental catastrophe in the form of the coal fire, which causes serious hazards like a landslide. These coal fires can occur in underground mines or at the Earth's surface(Tomlinson, 2014). Coal fires are a major problem for the developing nations from both from an economic point of view and also with regard to environmental pollution and the effect on human life (Yan et al., 2006). An outline of the theory, methods and case studies of identifying coal fires with remote sensing methods can be found in the paper by Biswal et al., 'Delineation and mapping of coal mine fire using remote sensing data - a review' (Biswal et al., 2019).

\footnotetext{
*Corresponding author
}

\section{STUDY AREA AND DATA}

\subsection{Study Area}

Jharia coalfield (JCF) has been taken into consideration for the examination of coal fires. It is present in Dhanbad district spread in the administrative blocks of Baghmara, Dhanbad, Jharia and very less area in parts of Baliapur. This area is located between latitude $23^{\circ} 35^{\prime} \mathrm{N}$ to $23^{\circ} 55^{\prime} \mathrm{N}$ and longitude $86^{\circ} 05^{\prime} \mathrm{E}$ to $86^{\circ} 30^{\prime} \mathrm{E}$. The coal field is spread over an area of $450 \mathrm{~km}^{2}$ approximately. The location of JCF is shown in Fig. 1.

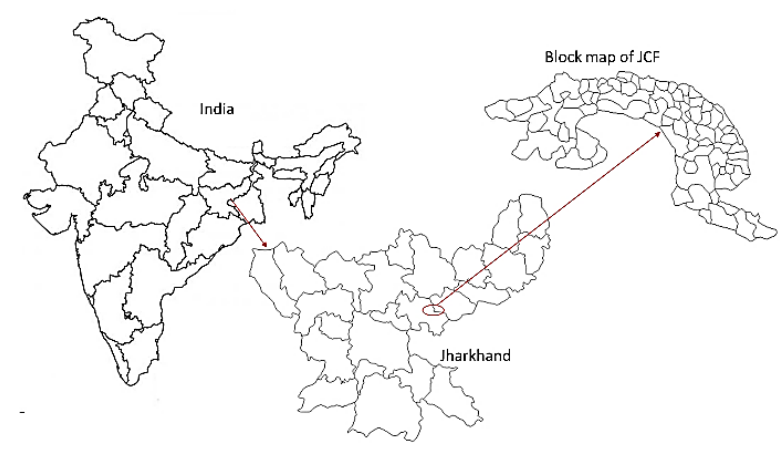

Figure 1. Location of Study Area

\subsection{Data}

A daytime band 13 of ASTER data acquired on $10^{\text {th }}$ Nov 2018 (04:55 AM) of WRS Path/Row- 140/44 and daytime band 10 of Landsat 8 OLI/TIRS (Operational Landsat Imager/ Thermal infrared sensor) data acquired on $9^{\text {th }}$ Nov 2018 (04:42 AM) WRS Path/Row- 140/43 has been used for delineation of coal fire in JCF. The details of the bands of two satellite used are given in Table 1. 


\begin{tabular}{|c|c|c|c|}
\hline Satellite & Band & $\begin{array}{c}\text { Wavelength } \\
(\mu \mathrm{m})\end{array}$ & $\begin{array}{c}\text { Resolution } \\
(\mathrm{m})\end{array}$ \\
\hline ASTER & Band 13 & $10.250-10.950$ & 90 \\
\hline Landsat 8 & Band 10 & $10.60-11.19$ & 30 \\
\hline
\end{tabular}

Table 1: Details of satellite data used

Both these data have been downloaded from the USGS website (https://earthexplorer.usgs.gov/).

The band 13 of ASTER dataset has very little emissivity difference of ground elements in the TIR band region, has been broadly used for coal fire delineation by previous researchers (Roy et al., 2015). The datasets of ASTER and Landsat nearly of the same wavelength and same month and year are chosen so that a comparison can be made and a similar technique can be used for datasets of different sensors.

A block boundary map (shown in Fig. (2)) of JCF was also generated from the surface map provided by BCCL, Dhanbad. A shape file of the geological map (as shown in Fig. (3)) was also prepared using the map provided by BCCL, Dhanbad.

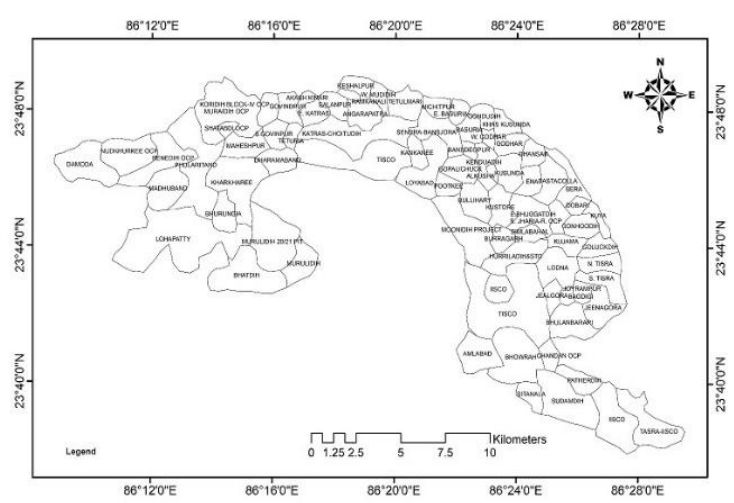

Figure 2: Block map of JCF

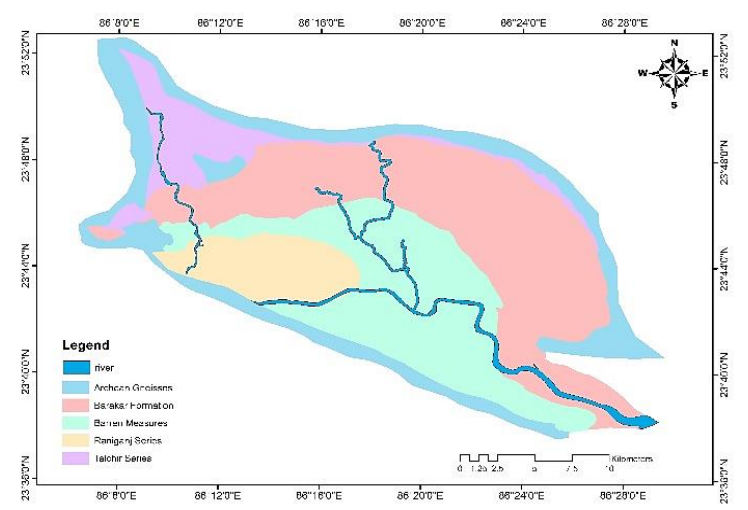

Figure 3: Geological Map of JCF

\section{METHOD}

\subsection{Processing of the ASTER data to predict the land} surface temperature

Band 13 of ASTER dataset that has been acquired is in hierarchical data format (HDF), and the values stored in it is in the form of a digital number (DN). Raw data which is the DN value is converted to top of the atmosphere spectral radiance using the following steps (Abrams et al., 2002)
$\mathbf{L}_{\text {rad }}=(\mathbf{D N}-\mathbf{1}) \times \mathbf{U C C}$

Where:

$$
\begin{aligned}
& \mathrm{L}_{\mathrm{rad}} \text { is the ASTER spectral radiance at sensor's } \\
& \text { aperture. } \\
& \text { UCC is the unit conversion coefficient }\left(\mathrm{W} \mathrm{m}^{-2} \mathrm{sr}^{-1} \mu \mathrm{m}^{-1}\right)
\end{aligned}
$$

The values of UCC for band 13 is given in Table 2. ASTER TIR products need to be recalibrated to correct for the temporal decline of the sensors. Therefore, the recalibrated spectral radiance $\left(\mathrm{L}_{\mathrm{rad}}(\mathrm{c})\right)$ is calculated from Eq. (2) (Tonooka et al., 2004).

$\mathbf{L}_{\mathbf{r a d}}(\mathbf{c})=\mathbf{A} \times \mathbf{L}_{\mathbf{r a d}}+\mathbf{B}$

Where:

A and B are the recalibrated coefficients and values and are generated from (Tonooka, 2019).

For band 13, values of A and B obtained are given in Table 2.

\begin{tabular}{|c|c|c|c|}
\hline Band & UCC & A & B \\
\hline Band 13 & 0.005693 & 1.007021 & -0.0412 \\
\hline
\end{tabular}

Table 2: Different coefficient values of ASTER band 13 data

\subsection{Processing of the Landsat 8 data to predict the land surface temperature}

The dataset of Landsat 8 i.e. acquired from USGS is in geotiff (.tif) format. The rescaling factors that come in the metadata file with the Landsat 8 data is used for conversion of pixel values (i.e. the $\mathrm{DN}$ value) to the atmosphere spectral radiance (Karen Zanter, 2019) using Eq. (3).

$\mathbf{L}_{\lambda}=\mathbf{M}_{\mathbf{L}} \times \mathbf{Q}_{\text {cal }}+\mathbf{A}_{\mathbf{L}}$

Where:

$\mathrm{L}_{\lambda}=$ Spectral radiance of Landsat $\left.8\left(\mathrm{~W} \mathrm{~m}^{-2} \mathrm{sr}^{-1} \mu \mathrm{m}^{-1}\right)\right)$ $\mathrm{M}_{\mathrm{L}}=$ Multiplicative rescaling factor from the metadata. $\mathrm{A}_{\mathrm{L}}=$ Additive rescaling factor from the metadata. $\mathrm{Q}_{\mathrm{cal}}=$ Quantized and calibrated standard product pixel values $(\mathrm{DN})$.

Eq. (4) is used for estimation of radiant (brightness) temperature from the spectral radiance $\mathrm{L}_{\mathrm{rad}}$ (c) (in case of ASTER Band 13) and $\mathrm{L}_{\lambda}$ (in case of Landsat 8 Band 10). Eq. (4) is the Planck's radiation function (Planck, 1914) which is the basic of derivation of radiant temperatures from the radiances of different spectrum of electromagnetic radiations and is deliberated in detail in various literatures (Becker, 1987). The Planks law is expressed as follows:

$\mathrm{T}=\frac{\mathrm{K}_{2}}{\ln \left(\frac{\mathrm{K}_{1}}{\mathrm{~L}_{\lambda}}+1\right)}-273.15$

where,

for band 13 of ASTER data:

$\mathrm{T}=$ radiant (brightness) temperature in ${ }^{\circ} \mathrm{C}$

$\mathrm{K}_{1}=$ calibration constant $\left(1350.05 \mathrm{~W} \mathrm{~m}^{-2} \mu \mathrm{m}^{-1}\right)$,

$\mathrm{K}_{2}=$ calibration constant $(866.47 \mathrm{~K})$,

$\mathrm{L}_{\lambda}=\mathrm{L}_{\mathrm{rad}}(\mathrm{c})=$ spectral radiance calculated from Eq. (3).

for Landsat 8 dataset:

$\mathrm{T}=$ radiant (brightness) temperature in ${ }^{\circ} \mathrm{C}$,

$\mathrm{K}_{1}=$ calibration constant $\left(774.89 \mathrm{~W} \mathrm{~m}^{-2} \mu \mathrm{m}^{-1}\right)$

$\mathrm{K}_{2}=$ calibration constant $(1321.08 \mathrm{~K})$, 
$\mathrm{L}_{\lambda}=$ spectral radiance calculated from Eq. (3).

The final output will give a radiant (brightness) temperature image in which the values represents the temperatures in Kelvin, so 273.15 is subtracted to get the value in ${ }^{\circ} \mathrm{C}$ spread all across JCF.

\subsection{Estimation of radiant (brightness) temperature image for delineation of sub surface coal mine fires.}

Once the radiant (brightness) temperature are derived from ASTER and the Landsat 8 datasets as shown in Fig. 4 and Fig. 5 , the next step was to separate out fire-affected areas from the non-fire areas, which needs to determine the threshold temperature. The radiant temperature image of JCF was studied, and the temperatures of each pixel were noted for further analysis (i.e., to estimate the threshold temperature) using scatterplot graph.

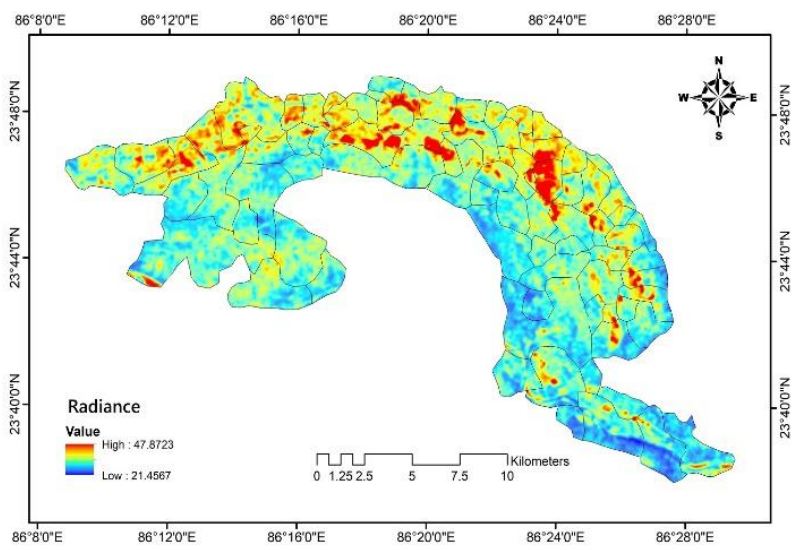

Figure 4: Radiant temperature image of band 10 (Landsat 8)

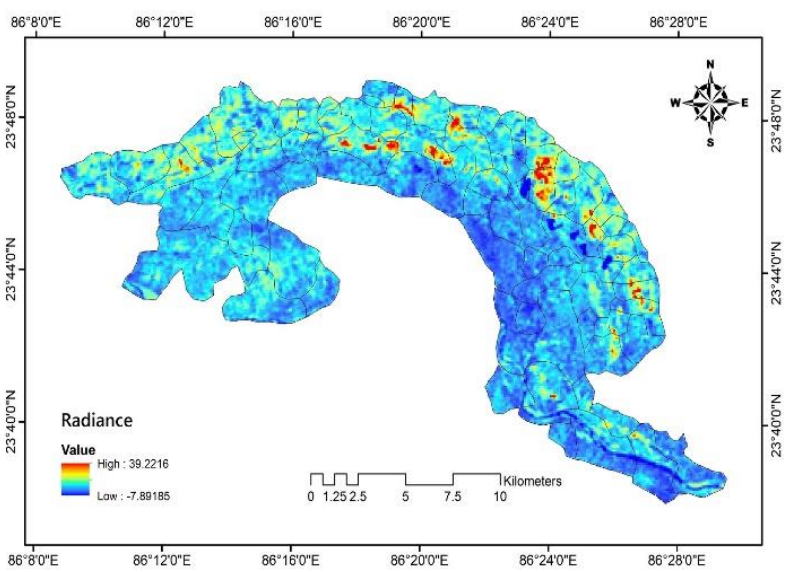

Figure 5: Radiant temperature image of band 13 (ASTER)

Mean and maximum radiant (brightness) temperatures were derived for different blocks of JCF. The scatter plot diagrams were generated between the mean and maximum temperature derived using band 10 of Landsat 8 and band 13 of ASTER separately. The respective plots are shown in Fig. 6 and 7. The maximum temperature derived was that of fire (if present), while the average temperature represents the regular background temperature.

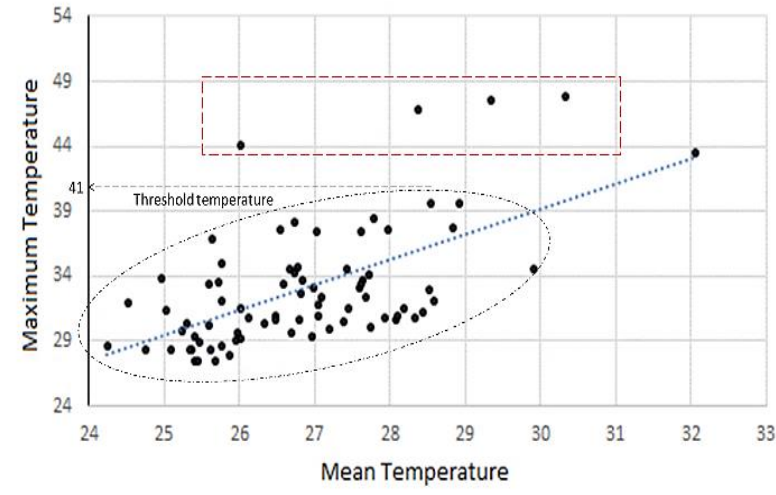

Figure 6: Scatter plot of maximum temperatures vs. mean temperature derived using Landsat 8 data

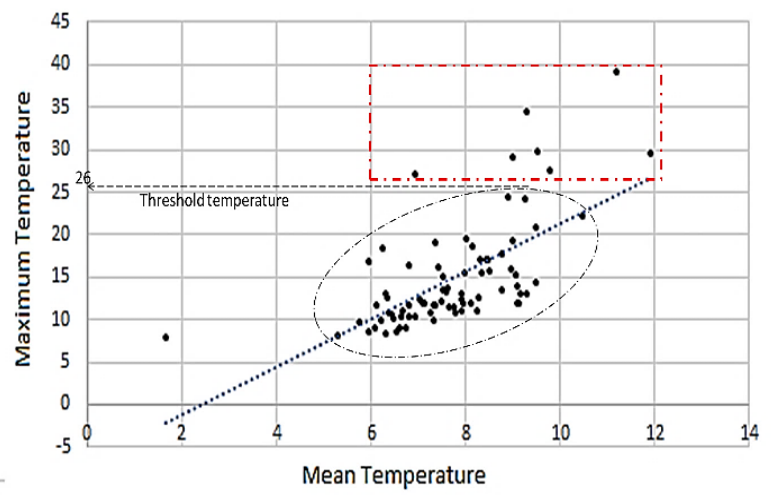

Figure 7: Scatter plot of maximum temperatures vs. mean temperature derived using ASTER data

In the case of the Landsat 8 data, the difference in temperature of the cluster was found to be in the range of $0^{\circ} \mathrm{C}-1^{\circ} \mathrm{C}$. Likewise, for ASTER, this difference was in the range of $1{ }^{\circ} \mathrm{C}-2^{\circ} \mathrm{C}$. It can be seen in Fig. (6) that clusters marked inside the dotted circle has a maximum temperature of $41^{\circ} \mathrm{C}$ and similarly in Fig. (7) it has a maximum temperature of $26^{\circ} \mathrm{C}$. Both the plots show two distinct clusters, the cluster bounded by the dotted circle represents the background temperature, and the cluster in a dotted rectangle in red represents the fire.

Hence, each of the clusters has a significant difference, which separates the coal fire from the background. The threshold temperature resulting from the cluster analysis is the extreme temperature of the background cluster, which signifies all those temperatures above this, is the temperature of coal fires. In the case of the Landsat 8 data, this threshold temperature is identified, which is nearly $41^{\circ} \mathrm{C}$, and in case of the ASTER, the threshold temperature is identified, which is nearly $26^{\circ} \mathrm{C}$. Based on this threshold temperature, two coal fire maps of JCF region was generated of $10^{\text {th }}$ and $9^{\text {th }}$ November 2018 for Landsat 8 and ASTER data, respectively.

\section{RESULTS AND DISCUSSIONS}

The implementation of threshold temperature resulting from the sampling of radiant temperature data of entire JCF enables the detection of the high-temperature fire zones indicative of coal fire pixels over the entire Jharia coalfield. Using the daytime TIR bands of Landsat 8 and ASTER data, major coal fire locations in JCF has been identified, as shown in Fig. (8) and Fig (9), respectively. 


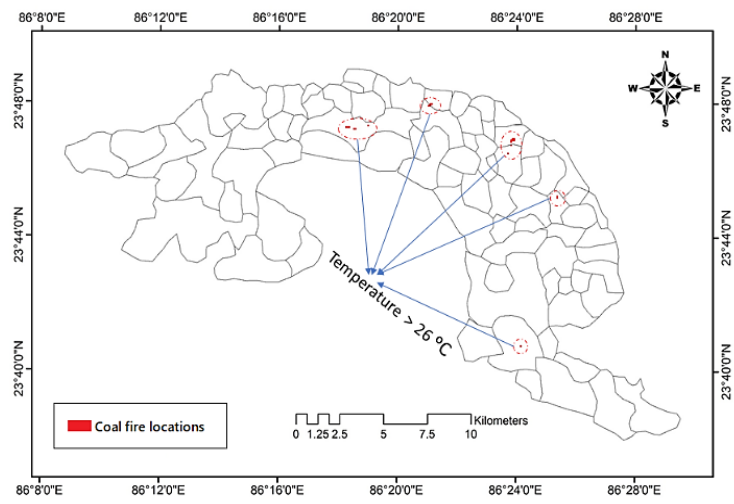

Figure 8: Fire map derived from ASTER band 13 data.

The variation of extents of background across the JCF may cause the threshold temperature to differ from one area to the other. Therefore, it is a challenging task to find suitable threshold temperatures in thermal data to segregate the fire pixels.

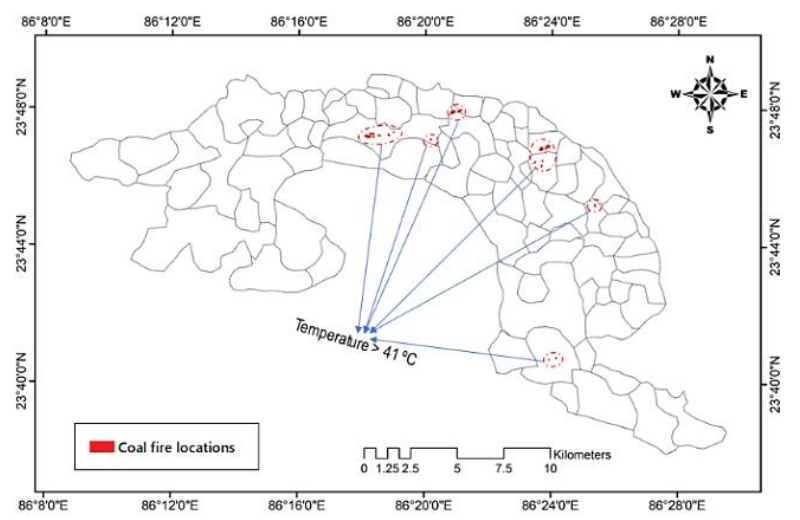

Figure 9: Fire map derived from Landsat 8 band 10 data.

In the current study, the threshold temperature is calculated by the separation of clusters of mean and maximum temperatures derived from different blocks of JCF from daytime Landsat- 8 and ASTER radiant temperature data.

It was observed that from Landsat 8 derived fire map, blocks of Katras-Choitudih, Sendra-Bansjora, Godhar, Kusunda, and Bhowrah were most affected by fires. Similarly, for ASTER derived coal fire map, blocks of Katras-Choitudih, SendraBansjora, Godhar, Kusunda, Bhowrah, S. Jharia R.OCP, and Nichitpur were mostly affected by the fire.

The coal fire map was overlaid on the geological map (Fig 3) of JCF area, and it was found that coal fires detected using the cluster technique was spread only on Barakar formation. Therefore, it can be said that the Barakar series are mostly affected by coal fires.

\section{CONCLUSIONS}

The study results revealed that the derived threshold temperature using cluster analysis facilitates the temperature profile in the coal fire regions as well as in the background regions. This cluster analysis method can be effectively used across various type of satellite sensorsCoal fire locations are identified using the threshold value in the entire coal field region. The threshold value generated from Landsat 8 and ASTER data will be useful in updating the fire zones in the coal mining regions from time to time. This opens a path for generating the fire maps using other satellite sensors as well.

The fires detected using Landsat 8 and ASTER data were found to be located in same blocks of JCF, but the differences in temperature exists. This may be due to the difference in the spectral resolution of ASTER and Landsat 8 datasets. These variations might also be due to the atmospheric conditions. However, the thermal contrast, which can be identified by satellites, of rocks and fire would remain constant from time to time with very negligible variations. Future work will focus on studying the impact of thermal atmospheric corrections, in determining the regional thresholds of coal fire maps derived for different seasons. The future work will focus on generating the fire maps of different years and detecting the change occurred in fire zones along with estimating the greenhouse gases emitted due to the coal burning.

\section{REFERENCES}

Abrams, M., Hook, S., Ramachandran, B., 2002. ASTER user handbook.

Becker, F., 1987. The impact of spectral emissivity on the measurement of land surface temperature from a satellite. Int. J. Remote Sens. 8, 1509-1522. https://doi.org/10.1080/01431168708954793

Biswal, S.S., Raval, S., Gorai, A.K., 2019. Delineation and mapping of coal mine fire using remote sensing data-a review. Int. J. Remote Sens. 40, 6499-6529. https://doi.org/10.1080/01431161.2018.1547455

Coal Information 2017, 2017. , Coal Information. OECD. https://doi.org/10.1787/coal-2017-en

Dillinger, J., 2019. The Top 10 Coal Producers Worldwide. URL https://www.worldatlas.com/articles/the-top-10-coalproducers-worldwide.html (accessed 7.15.19).

Karen Zanter, 2019. LANDSAT 8 (L8) DATA USERS HANDBOOK Version 4.0 April 20194.

Planck, M., 1914. The Theory of Heat Radiation.. translated by Masius, MP Blakiston’s Son \& Co.

Roy, P., Guha, A., Vinod Kumar, K., 2015. An approach of surface coal fire detection from ASTER and Landsat-8 thermal data: Jharia coal field, India. Int. J. Appl. Earth Obs. Geoinf. 39, 120-127. https://doi.org/10.1016/j.jag.2015.03.009

The Coal Resource, 2002. What is Coal?, The Coal Resource: A Comprehensive Overview of Coal.

Tomlinson, T., 2014. Coal fires : an Environmental Disaster. Tonooka, H., 2019. ASTER TIR Recalibration [WWW Document]. Toonka Laboratory. URL http://tonolab.cis.ibaraki.ac.jp/ASTER/RECAL/ (accessed 7.15.19).

Tonooka, H., Sakuma, F., Kudoh, M., Iwafune, K., 2004. ASTER/TIR onboard calibration status and user-based recalibration. Sensors, Syst. Next-Generation Satell. VII 5234, 191. https://doi.org/10.1117/12.514132 
Yan, G., Mas, J.F., Maathuis, B.H.P., Xiangmin, Z., Van Dijk, P.M., 2006. Comparison of pixel-based and objectoriented image classification approaches - A case study in a coal fire area, Wuda, Inner Mongolia, China. Int. J. Remote

Sens.

27 , $4039-4055$

https://doi.org/10.1080/01431160600702632 